\title{
IMPLEMENTASI SENSOR MEMS AKSELEROMETER SEBAGAI ALAT PENGUKUR GETARAN PADA TURBIN ANGIN
}

\author{
Fajar Aswin', Zaldy Sirwansyah Suzen \\ Jurusan Teknik Mesin, Politeknik Manufaktur Negeri Bangka Belitung, Sungailiat-Bangka, 33211 \\ e-mail: ${ }^{1}$ fajar.aswin@gmail.com
}

\begin{abstract}
Many techniques are available in the market to measure and analyze vibrations caused by rotating machines and the structure of the machine itself, but require expensive resources to identify the problem of damage. Generally these expensive equipment use conventional sensors such as eddycurrent sensors, swing coil velocity sensors and piezoelectric transducer sensors to measure vibration. The implementation of a vibration measuring device in the form of an accelerometer sensor with a type of Micro Electro Mechanical System (MEMS) and a signal processing unit (Arduino Mega microcontroller) is used to measure vibrations that occur in small-scale horizontal type wind turbine blades. Experiments were carried out to check the accelerometer's ability to detect vibration response on wind turbine blades with the free vibration position. Then the signal in the form of the time domain will be converted into the frequency domain to get the dominant frequency value of the turbine blade, which is then analyzed to be compared with the B \& $K$ VibroPort 80 vibration meter. The experimental results show that the MEMS type accelerometer sensor can be applied to measure the free vibration conditions on wind turbine blades with an error percentage below $6 \%$.
\end{abstract}

Key words: Vibration Measurement, MEMS Accelerometer, Wind Turbine, Fast Fourier Transform $(F F T)$

\begin{abstract}
ABSTRAK
Banyak teknik yang telah tersedia dipasaran untuk mengukur dan menganalisa getaran akibat mesin berputar maupun struktur bagian mesin itu sendiri, namun membutuhkan sumber daya yang mahal untuk mengidentifikasi masalah kerusakan tersebut. Umumnya peralatan yang mahal tersebut tersebut menggunakan sensor-sensor konvensional seperti sensor eddy-current, sensor swing coil velocity dan sensor piezoelectric tranduser untuk melakukan pengukuran getaran. Implementasi alat pengukur getaran berupa sensor akselerometer dengan tipe Micro Electro Mechanical System (MEMS) dan unit pemrosesan sinyal (mikrokontroler Arduino Mega) digunakan untuk mengukur getaran yang terjadi pada blade turbin angin tipe horizontal skala kecil.Percobaan dilakukan untuk memeriksa kemampuan akselerometer dalam mendeteksi respon getaran pada blade turbin angin dengan posisi free vibration. Signal dalam bentuk domain waktu akan diubah menjadi domain frekuensi untuk mendapatkan nilai frekuensi dominan sudu turbin yang kemudian dianalisa untuk dibandingkan dengan alat pengukur getaran B\&K VibroPort 80. Hasil percobaan menunjukan bahwa sensor akselerometer tipe MEMS dapat diterapkan untuk mengukur kondisi free vibration pada sudu turbin angin dengan prosentase error di bawah $6 \%$.
\end{abstract}

Katakunsi : Pengukuran getaran, sensor MEMS akselerometer, Turbin angin , Fast Fourier Transform (FFT)

\section{PENDAHULUAN}

Analisa getaran adalah teknik yang paling sering digunakan untuk pemantauan kondisi mesin berputar.Hal ini dikarenakan analisa getaran merupakan metode yang paling efisien untuk prediksi awal dan mendeteksi kegagalan system pada peralatan mekanis. Teknologi sensor terapan dipilih dengan mempertimbangkan rentang frekuensi dan kondisi operasional mesin. Sensor posisi, kecepatan dan akselerasi digunakan untuk rentang frekuensi rendah, menengah, tinggi dan sangat tinggi. Banyak teknik yang telah tersedia dipasaran untuk mengukur dan menganalisa getaran mesin, namun membutuhkan sumber daya yang mahal 
untuk mengidentifikasi masalah kerusakan pada mesin. Umumnya peralatan yang mahal tersebut tersebut menggunakan sensor-sensor konvensional seperti sensor eddycurrent, sensor swing coil velocity dan sensor piezoelectric accelerometer untuk melakukan pengukuran getaran [2].

Untuk mengatasi masalah biaya mahal, dewasa ini telah banyak dikembangkan alat pengukur getaran berbiaya rendah dengan menggunakan sensor dengan teknologi Micro Electro Mechanical System (MEMS). Dengan teknologi ini, biaya yang dibutuhkan kira-kira sepersepuluh dari accelerometer tipe Piezoelectric Tranducer (PZT) [4]. Teknologi MEMS adalah suatu sistem mikro dengan kemampuan fungsi elektromekanik baik sebagai mikrosensor maupun microactuator [1]. Sensor MEMS akselerometer merupakan sensor yang mempunyai teknologi MEMS dengan prinsip kerja yang sama dengan sensor konvensional. Sensor jenis ini bukan merupakan sensor yang umum digunakan dalam pengukuran getaran pada industri.

Beberapa penelitian yang terkait dengan penggunaan teknologi MEMS antara lain: [1], meneliti sistem pemantauan getaran memanfaatkan teknologi MEMS menggunakan sensor ADXL345 tiga sumbu dan papan mikrokontroler AT Mega dengan perangkat lunak LabView untuk penerapan di pesawat ruang angkasa. Hasil penelitian tersebut menunjukkan bahwa sensor MEMS digital ADXL345 mampu secara konsisten memantau sinyal getaran yang berbeda dengan akurasi yang baik; [4] mengembangkan penggunaan sensor MEMS accelerometer dua sumbu ADXL001, kartu akuisisi data tipe NI9234, dan perangkat lunak LabView digunakan untuk pemantauan kondisi getaran mesin perkakas dengan hasil nilai pengukuran akselerometer MEMS lebih besar dari pada akselerometer PZT kurang dari 6 persen dalam domain waktu; [3] menggunakan sensor MEMS ADXL 345 dengan sistem akuisisi data yang terhubung dengan papan Arduino Mega untuk mengukur getaran bantalan. Penelitian ini menghasilkan sistem pengukuran sederhana yang hemat biaya untuk industri skala kecil/menengah dan mendapatkan prosentasi error hasil pengukuran sebesar 3\% dalam domain waktu.

Dalam penelitian ini, sensor akselerometer Micro Electro Mechanical System (MEMSADXL345) dan unit pemrosesan sinyal (mikrokontroler) Arduino Mega 2560 akan digunakan untuk mengukur getaran yang terjadi pada turbin angin skala kecil tipe 300 Watt, 1,5 m diameter blade, dimana perangkat lunak Matlab R2017b akan digunakan untuk menganalisa respon getaran dalam domain frekuensi Fast Fourier Transform (FFT) yang merupakan teknik pemrosesan sinyal yang biasa digunakan untuk menganalisa getaran dengan cara mengubah sinyal pada domain waktu menjadi signal pada domain frekuensi.

\section{METODE PENELITIAN}

Penelitian dilakukan dalam tiga tahapan, yaitu dimulai dari tahap pengumpulan data dan penentuan desain eksperimen, kemudian dilanjutkan dengan tahap perancangan dan perakitan media uji (Turbin angin tipe 300 watt) dan alat pengukur getaran MEMS Akselerometer ADXL345 dengan pemproses signal Arduino Mega 2560, serta tahap akhir dengan pengujian respon getaran menggunakan akselerometer MEMS ADXL345 dan B\&K VibroPort 80 sebagai alat ukur pembanding yang dilanjutkan dengan analisis hasil pengukuran yang diolah dari domain waktu ke domain frekuensi Fast Fourier Transform (FFT) untuk 
mendapatkan nilai frekuensi dominan dari getaran yang diukur.

Gambar 1 menampilkan desain eksperimen media uji yang terdiri dari turbin angin tipe 300 Watt dengan 1,5 meter diameter blade, tower (penopang turbin angin), dan alat penjepit blade untuk pengujian (ragum meja). Salah satu blade dari turbin angin dilepas untuk dijepit pada ragum yang sebelumnya telah ditandai untuk masing-masing posisi pengukuran yang terdiri dari lima posisi dengan jarak antar posisi sepanjang $100 \mathrm{~mm}$.

Gambar 2 merupakan tampilan desain eksperimen alat pengukur getaran ADXL 345 dan VibroPort 80. Sensor Akselerometer ADXL 345 dan Tranduser PiezoElectric (PZT) dipasang berdekatan pada ujung blade yang akan diukur (posisi 5), posisi sensor mengukur pada sumbu horizontal untuk meminimalisir pengaruh berat sensor terhadap gaya gravitasi bumi. Untuk meminimalisir pengaruh redaman luar, kabel-kabel penghubung sensor ditempelkan ke badan blade dengan cara direkatkan dengan selotip kertas. Kemudian kabel ADXL 345 dihubungkan ke papan Arduino Mega 2560 yang telah diprogram untuk akuisisi data dari ADXL 345 ke komputer menggunakan jalur komunikasi data Inter-Integrated Circuit (I2C). Sedangkan PZT sensor dihubungkan ke unit pemroses VibroPort 80 untuk akuisisi data menggunakan fitur Time Signal Data Aquicision (DAQ). Hasil pengukuran kemudian disimpan dalam format $c S v$ untuk VibroPort 80 menggunakan media penyimpanan kartu memori dan dalam format Excell untuk data ADXL 345 yang disimpan secara langsung ke hardisk komputer menggunakan fitur Parallax DAQ.

Pada tahapan akhir penelitian, kedua data hasil pengukuran dianalisa menggunakan perangkat lunak Matlab versi R2017b professional. Hasil pengolahan data dalam bentuk domain frekuensi (Fast Fourier Transform, FFT) yang kemudian dianalisa secara statistik untuk tujuan pengambilan keputusan. Peubah yang diamati dalam penelitian ini adalah variabel posisi pembebanan eksitasi oleh palu lunak khusus pengukuran getaran pada 5 (lima) posisi pengukuran. Parameter lain yang diamati juga adalah perbandingan hasil analisa menggunakan sensor MEMS ADXL 345 dengan tranduser PZT tipe AS-60 merek B\&K.

\section{HASIL dan PEMBAHASAN}

Pengujian dilakukan dengan mengukur respon getaran terhadap blade turbin angin tipe 300 Watt pada posisi 1 sampai 5 dengan jarak antar posisi sebesar $100 \mathrm{~mm}$. Gambar 3 sampai gambar 7 merupakan tampilan hasil analisa dari domain waktu (Time Domain) menjadi domain frekuensi (Fast Fourier Transform, FFT) menggunakan perangkat lunak MATLAB R2017b.

Berdasarkan Gambar 3 sampai gambar 7, FFT hasil pengukuran menggunakan sensor MEMS ADXL 345 masih banyak terdapat noise yang dihasilkan dari pengaruh sensitivitas sensor dan frekuensi listrik yang dihasilkan dari sumber powernya. Untuk menghilangkan noise yang disebabkan oleh frekuensi listrik dapat ditambahkan kapasitor antara sumber power pada papan Arduino dan pin VCC-CS pada sensor MEMS ADXL 345. Secara data, frekuensi dominan yang muncul antara pengukuran menggunakan MEMS ADXL 345 dan Tranduser Vibroport 80 cenderung berjumlah sama, yaitu antara 3 sampai 4 frekuensi dominan. Hal ini menunjukan bahwa kemampuan sensor MEMS dalam hal pengukuran respon getaran pada blade turbin angin skala kecil masih dapat diterima. 
Data hasil analisa pada domain frekuensi (FFT) pada frekuensi dominan yang pertama muncul $\left(f_{1}^{s t}\right)$ untuk setiap posisi pengukuran disajikan pada Tabel 1. Dari Tabel 1, hasil pengukuran menggunakan ADXL 345 dengan pembebanan eksitasi pada posisi 3 dan 5 mempunyai prosentase error terbesar dibandingkan alat pengukur getaran referensi, yaitu sebesar 6,79 \%. Hal ini dapat dikarenakan posisi 5 adalah lokasi penempatan sensor getaran sehingga dengan dimensi akselerometer ADXL 345 yang sangat kecil tersebut akan sangat kecil kemungkinan menghindari pengaruh double hits dari pukulan palu eksitasi. Sedangkan persentase error terkecil berada pada pembebanan eksitasi posisi 4. Data pada posisi inilah yang paling optimal untuk mengukur respon getaran pada kondisi free vibration, karena letak sensor tidak kontak secara langsung dengan palu eksitasi dan juga merupakan titik terjauh dari clamp penjepit.

Secara umum, rata-rata hasil pengujian didapatkan bahwa kemampuan sensor MEMS ADXL 345 untuk mengukur respon getaran pada blade turbin angin skala kecil hampir menyamai kemampuan alat pengukur getaran tipe piezoelectric (PZT) yang digunakan pada Vibroport 80 dengan persentase error sebesar 5,96\%. Gambar 8 merupakan grafik persentase error pada domain frekuensi dari hasil pengukuran respon getaran.

Dengan batasan persentase error sebesar $10 \%$ terhadap nilai pengukuran dalam domain frekuensi yang dibandingkan dengan hasil pengukuran menggunakan alat pengukur getaran VibroPort 80, hasil pengukuran menggunakan sensor akselerometer ADXL 345 ini masih masuk dalam toleransi untuk masing-masing posisi pembebanan eksitasi. Nilai persentase ini hampir sama dengan penelitian yang dilakukan oleh [4] untuk mengukur getaran pada mesin perkakas menggunakan akselerometer dua sumbu yaitu sebesar kurang dari $6 \%$. Akan tetapi, berdasarkan penelitian yang dilakukan oleh [3] untuk mengukur getaran pada bantalan gelinding menggunakan MEMS akselerometer, persentase error yang mereka dapatkan lebih kecil dibandingkan persentase error pada pengukuran blade turbin angin ini yaitu, sebesar 3\%. Hal ini menunjukan bahwa pengukuran pada kondisi free vibration lebih sulit diterapkan menggunakan sensor akselerometer ADXL 345 dibandingkan pengukuran pada bantalan gelinding.

\section{KESIMPULAN}

Berdasarkan penjelasan pada Bab Hasil dan Pembahasan diatas, dapat ditarik kesimpulan bahwa untuk pengukuran respon getaran blade turbin angin skala kecil pada domain frekuensi menggunakan sensor akselerometer tipe MEMS ADXL 345 masih dapat diterima jika dibandingkan dengan alat pengukur getaran VibroPort 80. Akan tetapi, jika dibandingkan dengan hasil penelitian sebelumnya, sensor tipe MEMS ADXL 345 lebih akurat untuk mengukur getaran pada kondisi yang bukan free vibration. Hal ini disebabkan oleh pengaruh noise yang juga meningkat ketika pengukuranpada kondisi free vibration.

\section{UCAPAN TERIMAKASIH}

Penelitian ini dibiayai oleh Direktorat Riset dan Pengabdian Masyarakat Direktorat Jenderal Penguatan Riset dan Pengembangan Kementerian Riset, Teknologi, dan Pendidikan Tinggi dengan skema Penelitian Dosen Pemula tahun 2018. 


\section{DAFTAR PUSTAKA}

[1] Abraham, L., and P. Trivandrum. 2014. Vibration Monitoring Using MEMS Digital Accelerometer with ATmega and LabVIEW Interface for Space Application. Vol. 1, No. 5: 3-7.

[2] Broch, J. T. 1985. Mechanical Vibration and Shock Measurements, 2nd Soborg: K. Larsen \& Son.
[3] Feriadi, I., F. Aswin, dan M. I. Nugraha, 2017. Analisis Sistem Pengukuran Getaran MEMS Accelerometer ADXL345. Manutech J. (Jurnal Teknol. Manufaktur). Vol. 9, No. 2: 6488.

[4] Huang, C. Y., and J. H. Chen. 2016. Development of Dual-Axis MEMS Accelerometers for Machine Tools Vibration Monitoring.

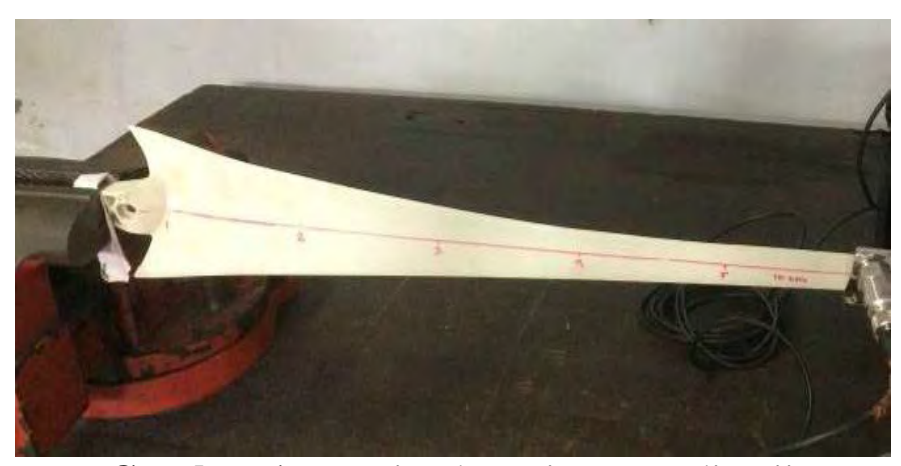

Gambar 1. Desain eksperimen media uji

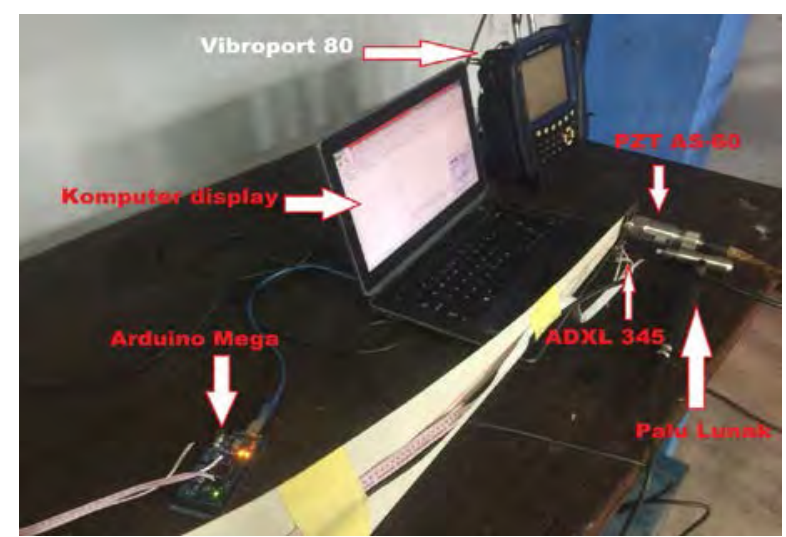

Gambar 2. Desain eksperimen alat pengukur getaran

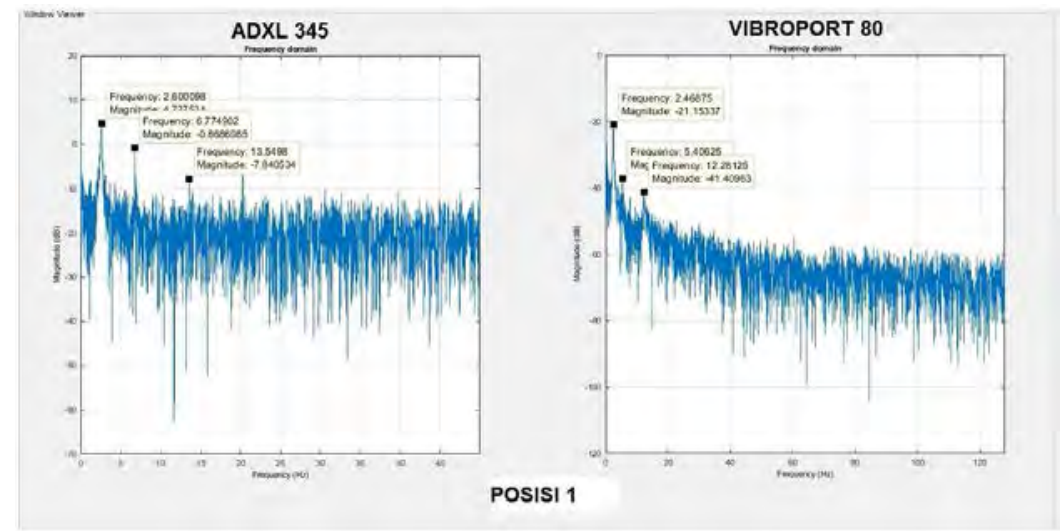

Gambar 3. FFT posisi 1 
Fajar Aswin dan Zaldy Sirwansyah Suzen, Implementasi Sensor Mems...

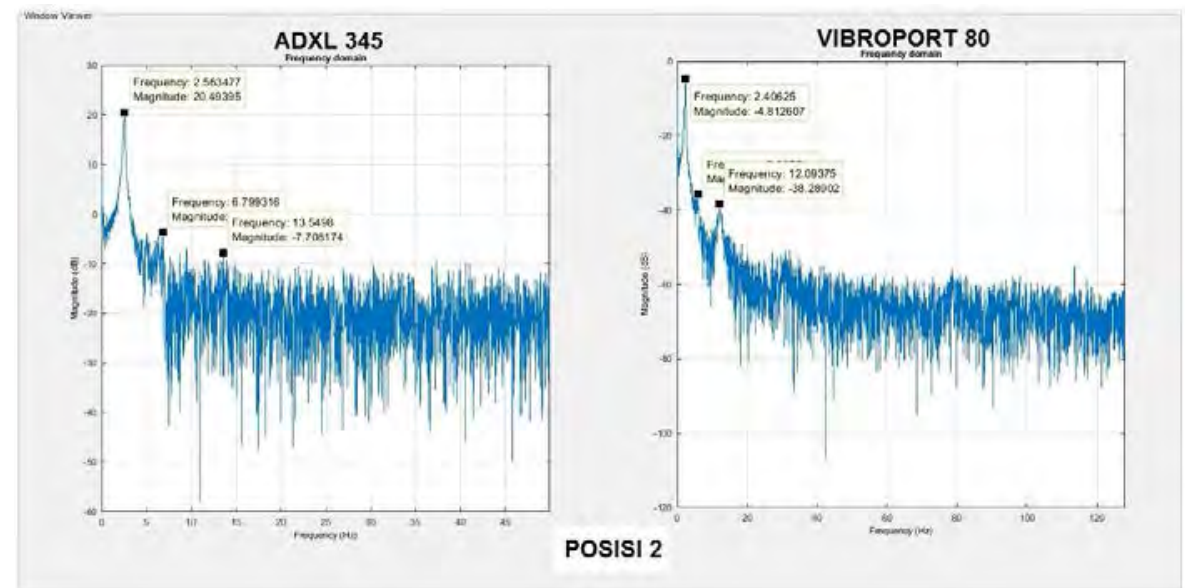

Gambar 4. FFT posisi 2

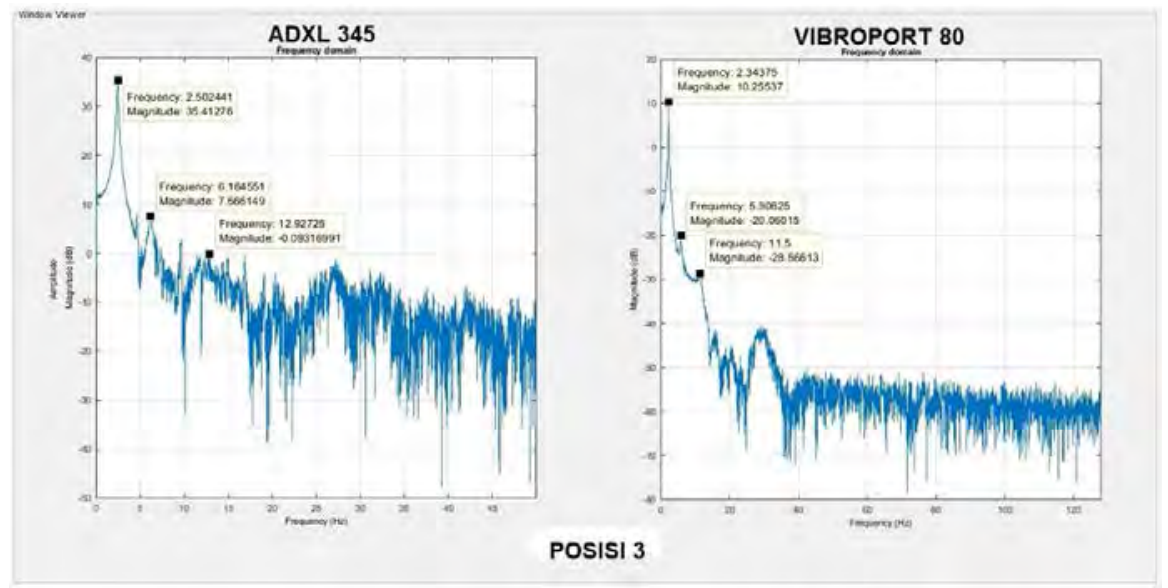

Gambar 5. FFT posisi 3
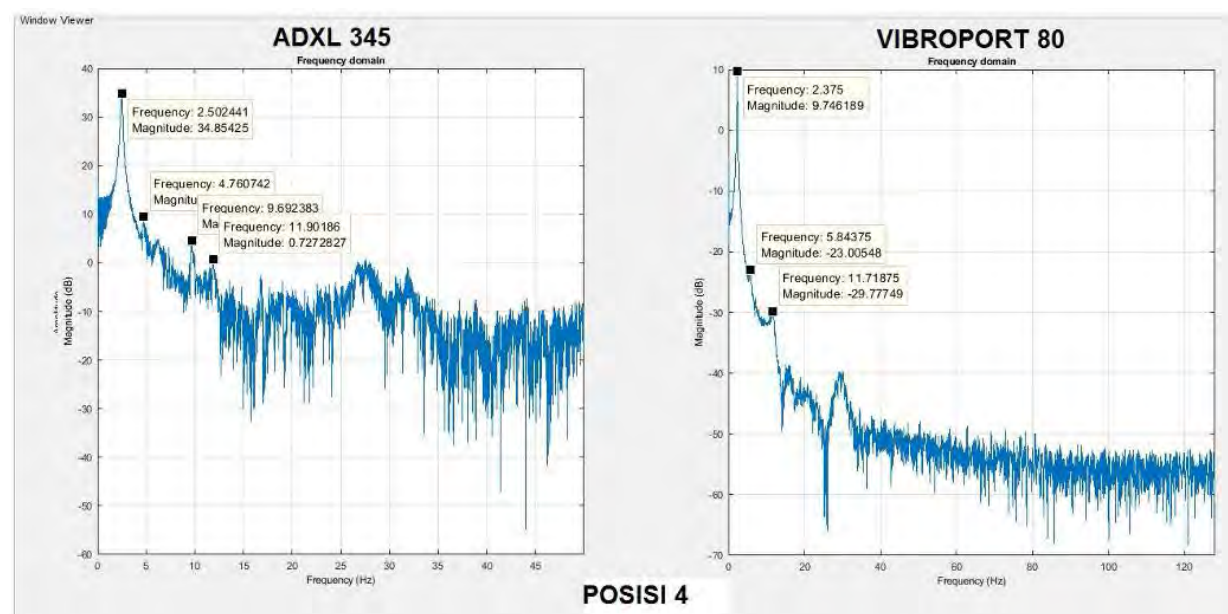

Gambar 6. FFT posisi 4 


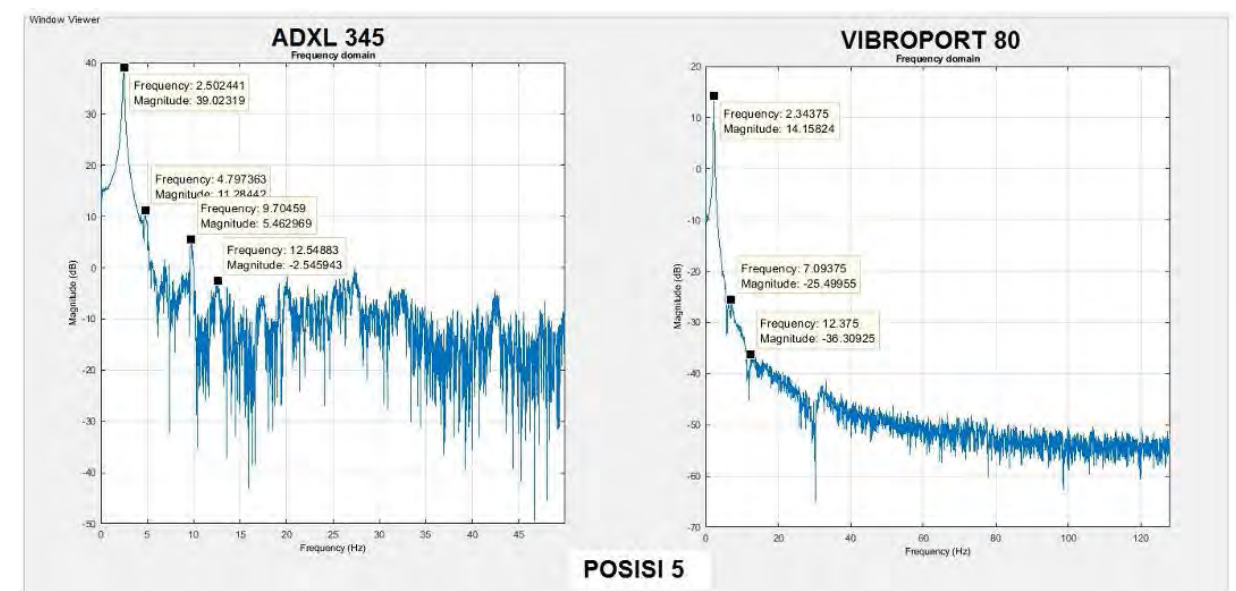

Gambar 7. FFT posisi 5

Tabel 1. Hasil analisa data pada frekuensi pertama

\begin{tabular}{|c|c|c|c|c|c|c|}
\hline \multirow{2}{*}{ POSISI } & \multicolumn{3}{|c|}{ Frekuensi (Hz) } & \multicolumn{3}{c|}{ Magnitude (dB) } \\
\cline { 2 - 7 } & ADXL & VIBRO & ERROR (\%) & ADXL & VIBRO & GAP \\
\hline 1 & 2,60 & 2,47 & 5,35 & 4,56 & $-21,15$ & 25,71 \\
\hline 2 & 2,56 & 2,41 & 6,53 & 20,20 & $-4,81$ & 25,01 \\
\hline 3 & 2,50 & 2,34 & 6,79 & 35,27 & 10,25 & 25,02 \\
\hline 4 & 2,48 & 2,38 & 4,34 & 34,86 & 12,75 & 22,11 \\
\hline 5 & 2,50 & 2,34 & 6,79 & 39,20 & 14,15 & 25,05 \\
\hline $\begin{array}{c}\text { RATA - } \\
\text { RATA }\end{array}$ & $\mathbf{2 , 5 3}$ & $\mathbf{2 , 3 9}$ & $\mathbf{5 , 9 6}$ & & & $\mathbf{2 4 , 5 8}$ \\
\hline
\end{tabular}

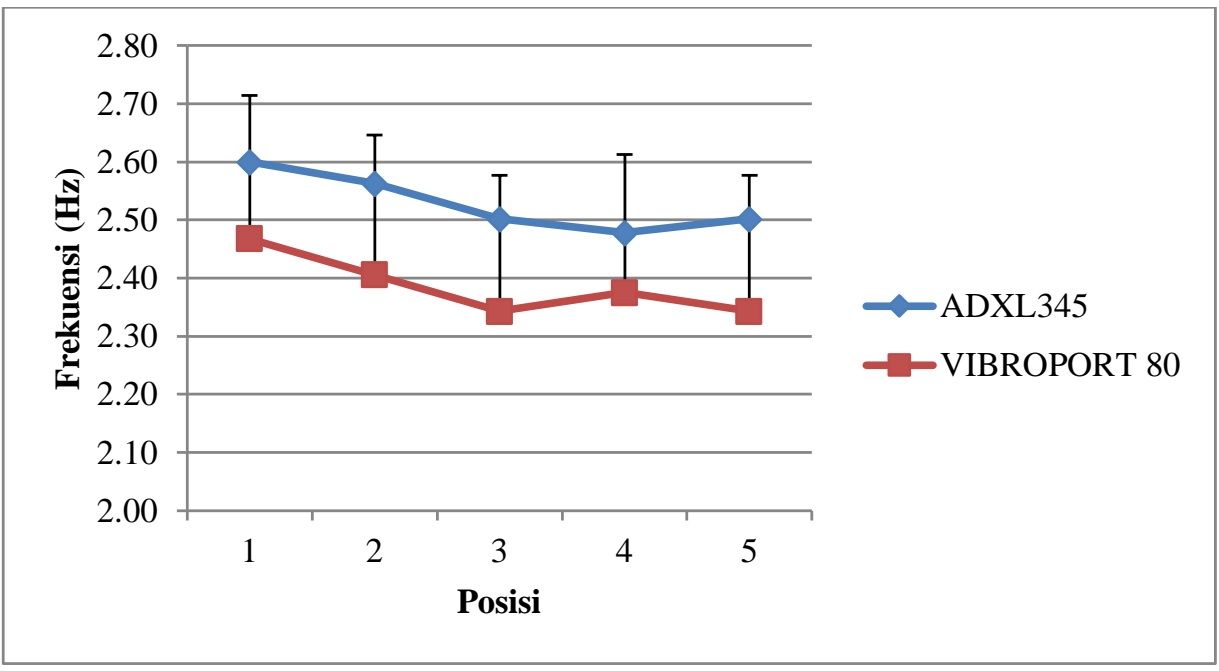

Gambar 8. Grafik persentase error pada domain frekuensi 
Fajar Aswin dan Zaldy Sirwansyah Suzen, Implementasi Sensor Mems... 